\title{
Problems and Remedies in Writing Skill
}

\section{K. Gurusamy}

\begin{abstract}
Communication is a process through which meaning is assigned, ascertained and conveyed. It is an attempt to create shared understanding through the replication of tautologies in the universe. This process requires a vast repertoire of skills in interpersonal processing, listening, observing, speaking, questioning, analyzing, gestures, and evaluating enables collaboration and cooperation. Over time the forms and ideas about communication have evolved through the continuing progression of technology. The progression of written communication can be divided into three informative communication revolutions. First the written communication emerged through the use of pictographs. The second happened when writing began to appear on paper and other media with commonly shared writing systems, leading to the mobility in written communication. The final stage is the transfer of information through controlled waves of electromagnetic radiation and other electronic signals. Though there are several means and modes of communication process to establish meaning, it is only the written communication which has been globally recognized to be a powerful means for communicating ideas. But not everyone could communicate easily through written communication. It is hard to achieve and requires a lot of practice and patience. This paper entitled "Problems and Remedies in Writing Skills" deals with the problems that one come across in writing and also suggests some remedial measures to overcome them.
\end{abstract}

Keywords - Communication, Issues, Remedies, Writing.

\section{INTRODUCTION}

\section{$\mathrm{W}$} information and principles into substantial arguments, and to convey meaning through well-constructed text. As Silva pointed out the observations made by Zamel in her ESL writing: Past, Present, and Future "The process of writing is non-linear, exploratory, and generative whereby writers discover and generate ideas as they attempt to approximate meaning" [1]. In the same article Silva also quoteed Mel Levine's observation, "writing is the highest form and most complex use of language that our students have to undertake" [2]. For instance, they have to activate and control. Writing problems refer to the situations when students face problems in some of the features of the writing skills such as the proper use of grammar, punctuation and spelling mistakes. When facing such problems students fail to produce a mistake-free piece of writing.

On comparison to speaking, writing is far more difficult in English. Even in mother tongue, speaking is not hard in par with writing. This implies that writing in a second language such as English is a daunting task to the learners. Writing skills imply considerable and regular practice in higher order like the development of ideas, organization of thoughts, etc. In real life, one communicates in the written mode out of a purpose. One has to inform or persuade the readers by narrating, describing, explaining, by arguing for or against something respectively.

Revised Manuscript Received on December 20, 2019.

Dr.K.Gurusamy,Associate Professor,Department of English, Kalasalingam Academy of Research and Education, India. k.gurusamy@klu.ac.in

\section{HURDLES IN WRITING}

The requirements essential for writing naturally leads one to face several hurdles in learning writing in English. Generally this is falsely construed by many students that they do not know grammar well. Though, Grammar is the necessary requirement for writing in English, the micro-skills too play a specific role in establishing the desired meaning in written communication. Despite grammar, students do not take the other (micro-skills) problems into consideration. There are certain writing norms that are to be followed for right interpretation of information such as grammar, spelling, and punctuation, logical sequence of words or sentences, and correct organization of ideas.

The problem in the grammatical parts seems to result from inadequate learning. Imperfect presentation of rules, letdown to study the rules, and attempt to build up sentences from the acquired limited knowledge is the reason for grammatical errors. One of the serious problems in writing part is using wrong spelling. It is because of phonological demonstration. It turns into too challenging to interpret the projected meaning. It seems that the spelling problem in writing is a determined one. It is applied not only to the students but even to the professional writers and academics. Most common problem in writing is the misappropriation of capital letters. The correct use of capital letter is a correct norm in writing and it is mandatory in almost all the languages. The misuse of capital letters may cause partly due to worst handwriting.

The punctuation problem reasons the poor practice in writing skills in English. Most of the students do not know the correct use of punctuation marks. To convey the information in the right manners... The problem of punctuation is not limited to any particular level but to all levels of students even in higher learning institutions. Contrasting to speaking, writing is not a spontaneous activity. Though all human beings without explicit instructions acquire speaking, on one hand, writing has to be taught on the other. It is a skill which involves a lot of compound, linguistic and philological operations, which are to be trained and learnt. The performance of writing is deprived of direct context of communication.

\section{GRAMMATICAL ERRORS}

The most common grammatical problems are the use of tenses, prepositions, articles as well as syntactical and subject-verb agreement errors.

\section{A. Wrong usage of tenses}

The most common grammatical error is in the use of the correct tense. Many students misuse the tense forms in the variety of context. Applying the correct tense in the appropriate context is a tough task. A good writer in English uses the tense forms meticulously. 
The wrong use of tense form causes the change of meaning. Some people misuse the tense form by using present continuous instead of simple present tense, and use simple present instead of present perfect, they use simple past instead of simple present. This may be due to L1 interference because according to the rules of grammar.

\section{B. Errors in the Use of Prepositions}

In the process of teaching and learning correct use of preposition plays a prominent role. Most of the Indian learners find it very difficult to place the correct preposition in the right context, only very few Indians can do this, and even the native speakers can't. It is a complex process.

Omission of prepositions is a large area of ambiguity for many students. They failed to practice it correctly and misuse the correct preposition and also they redundantly use a preposition where it is not needed.

\section{Syntactical}

A wrong word form error is an error done by the students; another tricky area for students to learn is the omission of the plural endings. The students fail to use the possessive's' correctly, and misuse the plural ending's'. Also, the incorrect usage of comparative adjectives is another problematic area for the students.

\section{Subject-Verb Agreement}

One of the crucial problems in writing is the Subject-Verb agreement. In this process the subject should agree the verb or verb phrase with number and person in constructing the sentences many students are inefficient in knowing the agreement between the subject and verb. In English according to the grammatical rule the subject must agree with the verb if the subject is masculine, the verb should respond to it and the same rule is applicable to the feminine also.

\section{E. Articles}

The learners jump down an article when they should have sued it. Substitute of the right article with the wrong one was done by most of the students and also they add a redundant article. It is imaginable that learners may have sometimes elapsed to use articles due to the intrusion of their first language and this explains the event of inter lingual mistakes.

Remedial measures to overcome the problems in grammar

- Grammatical concepts should be taught within the context.

- Highlight the mastery of syntactic ideas under study.

- Heavy grammar practice should be emphasized.

- L1 should not be used to simplify L2 grammar rules.

- Focus should be on the fluency, not just the correctness or accuracy of production.

- Grammar rules should be taught while integrated with other language skills.

- Focus of teaching grammar should not be on rote rules and memorization.

- Teaching strategy of grammar instruction should not be form-focused rather than communication focused.

\section{PUNCTUATION ERRORS}

Most of the students suffer a lot in applying the punctuation system correctly in their writings.

The following are the reasons for it.

- Absence of the capital letter at the beginning of new sentences.

- Rare capitalization for Proper nouns.

- Incorrect usage of the colon.

- Omission of semicolon.

- Absence of exclamation mark where ever required.

- Run-on sentences, with no full stops at the end of sentences.

- Poor or non- revision of what is written and leaving not enough space between words.

- Improper use of question marks.

- Hyphens are hardly used.

- Omission of comma after introductory elements.

The students are in need of learning the features of the English phonological organization, such as the way to punctuate a question mark and when to end a sentence.

Remedial measures to overcome the problems in punctuation

- Punctuation marks should be introduced within the context.

- Teachers should check the use of punctuation marks consistently.

- Teachers should help students to recognize the similarities and dissimilarities between the L1 punctuation system and the L2.

- Teachers themselves should use punctuation marks in their writing modules.

- Teachers should motivate the students to further research punctuation marks to scaffold their understanding.

- Teachers should help the students to develop their interest towards the use of the punctuation mark.

\section{SPELLING MISTAKES}

The spelling mistakes are caused by the following

- Replacement: This error caused by substituting a letter or more as another, replacing thee for the $\mathrm{i}$ in big (beg).

- Omission: This error is caused by omitting one letter or more, as neglecting the ' $\mathrm{f}$ ' in the word afect (affect).

- Addition: It refers to adding an additional letter or letters to a word, as adding an 'i' to the word aill (all).

- Disarranging: It refers to disordering of some letters in a word, such as writing 'becuase' (instead of 'because').

- Division: It refers to writing one word as two, or dividing the word, e.g. 'some times' (sometimes).

The foremost reasons for spelling errors are pronunciation, variances in the comprehensive systems of English. Over generalization, illogical nature of English 
word derivation, imperfect application of spelling rules, or the deficiency of understanding the exceptions of spelling rules, and recital errors

Remedial measures to overcome the problems in spelling

- Teachers should draw students' attention to the fact that the origin of English words makes learning their spelling difficult.

- Students should learn the phonological differences between L1and L2.

- Students should read more.

- Textbooks should help students to develop their spelling proficiency.

- Students should sharpen their interest to learn spelling.

- Teachers should be trained enough to help the students in overcoming spelling deficiency.

\section{CONCRETE STEPS TO OVERCOME THE PROBLEMS IN WRITING}

To overcome the writing problems in the language environment, it is the responsibilities of both the teacher and the students.

- Class room assignments should be given with lot of individual exercises for the students in the classes during their free time and at home.

- Writing Techniques should be taught with effectively, and make them to practice in writing an introduction, conclusion, overview, changeover of words and Thesis statement etc.

- The writings of the students' samples ought to be transliterated and circulated to them for improvement and analysis, from this practice the students can improve their writing skills from the mistakes, if they committed.

- To decrease students' fear of failure the teachers should motivate them to achieve victory by saying that punishment will not be given for the mistakes unless the errors distort their intended meaning and make them confident.

- The classroom environment should be friendly, helpful and cooperative enough to help students overcome their writing anxiety.

- Students should receive clear instructions and sufficient guidance about how to perform the writing task.

- Teachers should personalize and simplify the topics to make them easier, more interesting and relevant to the students' liking and everyday real-life situations.

- Writing exercise should be constructed on the students' requirements and capabilities.

- Teachers should draw their students' attention to the fact that good writers are basically good readers.

\section{CONCLUSION}

Writing is not an easy skill to be learnt with ease. On comparison with other communication skills and strategies writing demands the message conveyor as well as the receiver to have mastery over the language as well as the criteria in which it occurs. Even the native speakers are facing problems in the correct usage of writing. To become a good writer and to gain mastery over the writing skill, it is imperative that one need to possess world knowledge and vocabulary, professional knowledge and structural skills in addition to that of grammar. Consequently, a high level of written English is possible only when one puts enormous hard work in constructing his knowledge of the areas mentioned above.

\section{REFERENCES}

1. Silva, T. "ESL writing: Past, present, and future". HOW. A Colombian Journal for Teachers of English, 10, 28-39. 2003. Print

2. Ortega, L. and Rodríguez, V. "Improvement of writing proficiency through creation of homogeneous groups in the classroom". PROFILE. Issues in Teachers'Professional Development, 1, 48-51. 2000. Print.

3. White, R. and Arndt, V. Process writing. Longman: London and New York. 1991. Print.

\section{AUTHORS PROFILE}

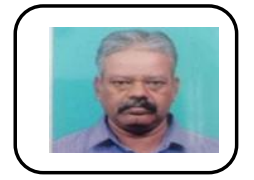

Dr. K. Gurusamy, Associate Professor in the Department of English, Kalasalingam Academy of Research and Education ,Krishnankoil, Virudhunagar District,Tamilnadu,India, has completed his graduation, post-graduation and M.Phil. in English Literature from Madurai Kamaraj University, Madurai, India. He was awarded Ph. D. at Kalasalingam Academy of Research and Education, Krishnankoil, India on March 2017,on the topic entitled English Language Teaching with Special reference to Technical communication..He has been teaching English for the Engineering students for more than a couple of decades and also teaching English literature to the UG, PG and research scholars. He has guided more than $10 \mathrm{M}$. Phil. scholars and several M. A. projects. His research area includes English Language Teaching, Indian writing in English, Post Colonialism and Modern Literature. He has published 5 papers in International refereed journals and among them, 2 papers are UGC approved. He has participated in more than10 conferences and workshops in both National and International levels. He is an authorised trainer for Cambridge ESOL Examinations, and has been training the students for BEC (Business English Certificate) Examinations for more than a decade. He is an authorised Speaking Examiner for BEC Speaking Examinations from 2018 onwards. He is a life member of ISTE. 